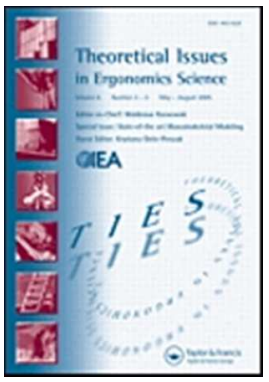

\title{
A comprehensive tool for developing new human-centred and social inclusion-oriented design strategies and guidelines
}

\begin{tabular}{|r|l|}
\hline Journal: & Theoretical Issues in Ergonomics Science \\
\hline Manuscript ID & TTIE-2017-0051.R1 \\
\hline Manuscript Type: & Research Paper \\
\hline Keywords: & $\begin{array}{l}\text { Human-Centered Design, Design for Social Inclusion, Interdisciplinary } \\
\text { Approach, Design Research, New Design Tool }\end{array}$ \\
\hline \multicolumn{2}{|c}{} \\
\hline
\end{tabular}

\section{SCHOLARONE"}

Manuscripts 


\title{
A comprehensive tool for developing new human-centred and social inclusion-oriented design strategies and guidelines
}

\author{
While Human-Centred Design is by the time considered a consolidated design \\ methodology, emerging social inclusion-oriented theories need to be more \\ comprehended in order to understand their potential applications in the \\ development of new design solutions. This sort of discrepancy often generates \\ contradictory phenomena: solutions developed using such approaches cannot be \\ considered, at the same time, fully human-centred and social inclusion-oriented. \\ The purpose of this article is to describe a new comprehensive tool, conceived \\ both for designers and researchers, able to develop human-centred and social \\ inclusion-oriented design strategies and guidelines. The tool, which is called \\ 'HSDT' (Human-Social Design Tool), is an easy-to-use methodological \\ instrument useful to identify focused results oriented toward Human-Centred \\ Design and Social Inclusion. Using logical sequences, it allows to develop new \\ conceptual definitions for both design and non-design subjects into new human- \\ centred and social inclusion-oriented records. Theoretical foundations, \\ methodological approaches, development stages and applications in design and \\ non-design areas are presented and discussed to demonstrate real benefits \\ resulting from the introduction of a new type of interdisciplinary tool and, later, \\ the opportunity for designers and researchers to adopt new problem-solving \\ approaches to bridging the gaps within Design literature.
}

Keywords: human-centred design; social inclusion; new tool; interdisciplinary; design strategies and guidelines

\section{Introduction}

Over the years, Human-Centred Design approach (HCD) has became pervasive and widely accepted in many design areas, both those concerning the development of tangible products like fast moving customer goods, and those related the creation of intangible ones like services and interactive applications (Giacomin, 2015). This rapid growth allowed to create a consistent number of methods and methodological tools, helping designers and researchers to develop effective solutions based on end-users' 
capabilities and needs (Buchanan, 2001). For example, usability heuristics (e.g., Nielsen, 1994) helps to conceive, prototype and test industrial products; task analyses (e.g., Annett, 2004; Stanton, 2006) are often used to plan and verify the functioning of services; anthropometric standards (e.g., Nowak, 1996; Pheasant and Haslegrave, 2005) help to correct global dimensions of products for specific regional markets; and so on. Accordingly, traditional structured HCD methods and tools consider the role of endusers during the interaction with products as one of the main elements of the entire design process.

The central role of humans is one of the fundamental pillars for Design discipline and Human Factors research being, probably, the most important elements to be taken into account for the development of effective successful products and services for global markets (Verganti, 2008). Recent studies have also pointed out that HCD shows an intrinsic interdisciplinary attitude, widely connected with the idea of human wellbeing (e.g., Krippendorff, 2007; Bazzano et al., 2017; Steen, 2011; Lofthouse and Prendeville, 2018), proposing to consider holistically the overall condition of end-users (i.e. needs, desires, experiences, social conditions, context of use). Furthermore, the International Standard Organization (ISO) re-considered the value of HCD in connection with traditional Human Factors' methodologies for human-system interaction, such as: usability, validations, stakeholders' involvement (ISO 9241-210, 2010). Accordingly, HCD is defined as:

\footnotetext{
Human-centred design is an approach to interactive systems development that aims to make systems usable and useful by focusing on the users, their needs and requirements, and by applying human factors/ergonomics, and usability knowledge and techniques. This approach enhances effectiveness and efficiency, improves human well-being, user satisfaction, accessibility and
} 
sustainability; and counteracts possible adverse effects of use on human health, safety and performance.

On the basis of the definition proposed by ISO (2010), HCD is based on six principles, listed as follow:

- The design is based upon an explicit understanding of users, tasks and environments.

- Users are involved throughout design and development.

- The design is driven and refined by user-centred evaluation.

- The process is iterative.

- The design addresses the whole user experience.

- The design team includes multidisciplinary skills and perspectives.

Compared to past User-Centered Design (UCD), HCD is then considered as an empowered approach, addressing the impact on a number of stakeholders, not just those typically considered as users (ISO 9241-210, 2010).

While HCD may be considered as an anthropocentric approach, recent interdisciplinary theories and studies are reconsidering the role of end-users in a more positive, holistic and socially oriented perspective. From the idea of 'standard endusers', the new vision considers the social dimension as a new factor that increase the value of end-users' interactions with products, promoting also the sense of social inclusion in a broader and aware way (Ornelas and Gregory, 2009). Social Inclusion mainly promotes this consciousness, as a radical position in antithesis with postFordism and mass production believes. 
In Design, Social Inclusion (SI) ${ }^{1}$ is today one of the most promising approaches that can be used for the ideation of a wide range of solutions, both small and large, both tangible and intangible (Keates \& Clarkson, 2002; Clarkson et al., 2003). It is based on a new positive role of 'real end-users' (Cappo, 2002), which have real needs, capabilities and socio-cultural desires. Accordingly, it takes a clear antithetic position from the typical user-centred design approach (Welch, 1995; Follette Story et al., 1998). The main concept revolving around this new idea is giving rights to all possible endusers to enjoy of any kind of designed solution in a more accessible, pleasant and sustainable way (Accolla, 2009). In doing this, the change of paradigm, from standard end-users to real ones, implies to consider both positive aspects (i.e. human proportion, capabilities, technological skills, positive cultural attitude, cosmopolitan mentality, etc.) and the negative ones (i.e. human disabilities, handicaps, anthropometric diversities, physical discordances, social stigmas, behavioural insufficiencies, etc.) (EIDD, 2004); compared to traditional design approaches, it therefore extends the potential of design solutions in the achievement of new goals but, at the same time, it imposes serious reflections on the manner through which solutions are conceived, tested and, finally, produced (Rossi and Barcarolo, 2013).

\footnotetext{
${ }^{1}$ There is a wide terminological debate on the correct name attributed to the design approach that promotes the goal of inclusion of people in the everyday life; this because the idea of inclusion can be developed in many ways, and throughout years it has been linked to many other meanings, including: accessibility, integration, empowerment, autonomy of use, prevention of social exclusion, design for disability, etc. Based on the geographical areas, it can be called as 'Universal Design' (USA, Japan and Norway), 'Inclusive Design' (UK) and 'Design for All' (in many countries of Europe). Because the purpose of this article is not to describe the terminological and methodological differences between such approaches, the term 'Design for Social Inclusion' will be used in a broader sense referring to all design activities aimed to include people in their everyday life through the principles of social inclusion.
} 
In addition, the rising of SI-oriented design studies published in last ten years underlines the great interest expressed by researchers, designers and professional communities worldwide (e.g. Dong, 2009; Goodman-Deane et al., 2014; Clarkson and Coleman, 2015; Di Bucchianico, 2015).

Although HCD is largely accepted as an approach in designing effective solutions, SI in Design is suffering by its complex nature and by the lack of common methodologies that could help professionals in their daily design activities. The understanding of all possible social and human aspects that can be included in the design of promising solutions increases the level of complexity of the entire design process, both if we create physical solutions and, mostly, if we develop strategic visions from non-design-oriented disciplines (Rossi, 2014). In fact, designers use methodologies or modified techniques belonging to other areas of design research; for example, in the accessibility of building it is common to see anthropometric standards used to guarantee the accessibility of people within environments (e.g., human-centred idea), rather that using holistic approaches to conceive pleasant environments where psychophysical characteristics are valorised (e.g., social inclusion vision that prevents social stigmas). Therefore, a large part of those solutions so-called 'inclusive', are only human-centred solutions with some enriched element taken from the SI domain; these solutions are not the result of a scientific approach, but consequences of designers' personal experiences, namely their good sense. In other words, designers are not really able to design inclusive-oriented solutions because they don't have design tools able to support the entire development process following the goals of SI.

Recognising the great value of HCD as an approach used to design industrial solutions, namely products and services, it is believed that the introduction of a new tool able to really help designers, but even researchers, to approach every issues with a 
scientific inclusive-oriented problem-solving approach could meet both HCD methodological potential and the novelty introduced by the new idea of SI. In fact, when SI is applied to the design domain, the need to adopt a common approach able to make clear the various elements to be considered can surely make easier and homogeneous the design process, accelerating the learning processes and giving the possibility to establish a new methodological transition toward human-centred and social inclusion-oriented solutions.

\section{Motivations: intrinsic constrains for HCD and design for SI}

The analysis on the current state of the art of methodologies, tools and of work-related actions performed by designers in the development of human-centred and social inclusion-oriented solutions allows to identify three main elements affecting the good diffusion of a shared culture for inclusive-oriented solutions. These elements, outlined as 'intrinsic constrains', are synthetically described below in order to understand their relevance for the purpose of this study and for the motivations behind the development of a comprehensive methodological design tool.

The first constrain concerns the discrepancy between HCD and design for SI approaches, which indirectly don't allow the creation of 'combined' tools to be used for the elaboration of design results, such as: design criteria, strategies and design guidelines. Though in HCD approach there are a wide number of methods and tools verified by an extensive literature and confirmed by cases study analyses (e.g., Maguire, 2001), in design for SI researchers are still working on its theoretical-methodological definition (i.e. Rossi and Barcarolo, 2015); in doing so, it is more closer to a goaloriented approach not supported by own methodologies. This generates the obvious consequence that, at the moment, it is not possible to develop any kind of solutions 
using simultaneously HCD and design for SI. Even though in last years some early results have been developed (e.g., Di Bucchianico, 2011; Di Bucchianico et al., 2012a; 2012b), the only thinkable way is to create a solution through the HCD approach and, then, incrementing its performance with additional insights form SI; while it seems to be more closes to a 'correction' approach, which has been demonstrated to be disadvantageous in terms of time and economic effort compared to the 'conception' one (Bandini Buti, 2008).

The second constrain is a direct consequence of the first one, above described. Principally it is linked to design for SI. While sometimes it is possible applying the principles of SI, in design practice they often seem to be only basic recommendations on how to design in an 'inclusive' way, vanishing their intrinsic potential in the achievement of really socially oriented goals; there is a theoretical gap within the literature that lets designers and researchers to operate in an arbitrary and iterative way. This aspect generates two different but similar effects both on the professional point of view and on the scientific one. On the professional point of view, the lack of theoretical foundations generates iterations; designers intuitively apply the principles of SI according to their belief, their professional experience and, finally, their sensitivity to predict and anticipate social factors in the user-product interaction. As a consequence, this behaviour doesn't generate a shared culture for the design of inclusive-oriented solutions and, therefore, other professionals don't have the chance to learn the 'what' and the 'how' to do to meet the principles of SI. On the scientific point of view, the lack of shared methods produces the so-called 'black box condition' (Buckley et al., 2010), where the start (input) and goal (output) of a process are clear and known, or at least they are predictable, but the logical steps that lead from the initial stage to the final one 
are not clear. Figure 1 describes the 'black box condition' considering the lacks within design for SI.

Figure 1 about here

In addition, the 'black box condition' generable by the lack of clear research paths on the understanding of human's condition is also in contrast with the first and the second general principle of HCD, namely: 'the design is based upon an explicit understanding of users, tasks and environments' and 'users are involved throughout design and development' (ISO 9241-210, 2010).

The third constrain refers to a common problem between HCD and design for SI: the applicability for non-design issues. In last years some important researches (e.g. Manzini, 2007a; 2007b) have investigated the potential application of design research in non-design issues with theoretical foundation within life sciences, social innovation, economics and politics; in these areas, it has been demonstrated that the Design discipline can play a crucial role, producing remarkable results for what concerns the envisioning of promising design scenarios to be tacked in the near future. Therefore, considering the limit of HCD in non-design issues and the general methodological lack of design for SI, a their potential applications for non-design fields can be seen as a proactive way of thinking able to meet a fast-growing culture for new design studies.

\section{Objectives: developing a comprehensive tool}

On the basis of the analysis of the three constrains before discussed, the aim of this study is to develop a comprehensive tool for generating new human-centred and social inclusion-oriented design strategies and guidelines. Accordingly, such tool has to 
combine both HCD approach and design for SI insights.

However, it is believed that the idea to combine these approaches can produce a number of positive effects, resulting from the combination of strengths from both sides. To be more precise, HCD can increase its value as design approach, extending its influence even in the field of SI; on the other hand, design for SI will benefit from the entire methodological HCD approach that is currently missing of foundations. At the same time, the combination of both approaches can act as a holist process, increasing the quality of overall results.

This study pursues two specific aims listed below:

- Exploring the hypothesis that it is possible to develop a methodological design tool combining both HCD and SI strengths and, thinking holistically, it should be more effective of the sum of both.

- Providing to designers and researchers a higher control on the research and design phases, using a tool that can act both as a learning methodology and a sharing instrument for experiences and knowledge.

Additional aims also concern:

- The development of a tool able to obtain open and comparable information (e.g it has to work with data from different subjects creating standardizable design parameters, conserving their original meanings).

- The development of a tool able to work with factual data (e.g. it has to work using Qualitative Research Approaches (QLR) (e.g., Kothari and Garg, 2014)). 


\section{Development of the Human-Social Design Tool (HSDT)}

The development of a new methodological tool has required a complex research process based on multiple approaches, including literature reviews, experimental analyses, methodological inductions (e.g., action-research). In this part, the complete process of development will be presented and discussed in order to show the various steps needed to achieve the theoretical goals of this study. The testing phase will be presented in the section five.

\subsection{Theoretical and methodological references}

An extensive literature review has been conducted in the areas of Design Research and Ergonomic Design, which allowed to select a QLR tool recently presented by Marano et al. (2012) and used within an experimental study in the cross-sectorial field of 'Ergonomic Design for Sustainability'. The tool (Figure 2), from the systematization of notions, definitions and relevant themes composing the Ergonomic Design discipline, proposes a terminological and conceptual elaboration for new design principles, criteria and strategies in line with the scientific impact and the cultural meaning of Sustainable Development (SD) (sustainability-oriented outcomes). Specifically, the process of development is composed by step-by-step learning and methodological phases, which adopt mutual interpretations among theoretical foundations of Ergonomic Design and the some relevant key principles of SD.

Figure 2 about here.

From the results obtained by this experimental study, authors have outlined a possible terminological definition for the new domain of 'Ergonomic Design for 
Sustainability' (EDS), and a number of specific design strategies and promising research themes have been developed as novel paradigms and original fields of experimentation for the new EDS.

Therefore, considering the great potential shown by this tool, it has been selected as a methodological reference for the purpose of this study; in fact, the originality of results achieved by the proposed process of interpolation was completely in line with the aim needed by this study. However, the only necessary modification needed was referred to the understanding of which elements have to be changed in order to evolve the tool from EDS to the new one that combines HCD and SI.

\subsection{Modifications needed for HCD and SI}

It is possible to develop the new human-centred and social inclusion-oriented tool analysing the one proposed for EDS and, in particular, reviewing the description proposed by authors on its development process (Di Bucchianico et al., 2012c), which is composed by three phases:

Phase 1: Definition of a theoretical framework of Sustainability: The first phase concerned the definition of a conceptual framework of knowledge about Sustainability. Basic notions of sustainable development have been identified and analysed through its objectives and its different dimensions [...] The interpretative analysis of these Sustainable Principles allowed, to point out some Keywords composed by terms and expressions used later to define some 'New Themes' characterizing Ergonomics for Sustainability.

Phase 2: Individuation of multidisciplinary criteria of Sustainability: The second phase has analysed a sample group of disciplines already oriented toward Sustainability [...] In this way it was possible to outline a common logical process of interpretation and elaboration that has allowed [...] to define criteria and indexes, guidelines and standards for Sustainability. In fact, from the critical review of the achieved results is derived a logical-interpretative model adopted later in the construction of a specific 'Ergonomics for Sustainability Thematic Table'. 


\begin{abstract}
Phase 3: Construction of the Ergonomics for Sustainability Thematic Table: The 'Ergonomics for Sustainability Thematic Table' is divided in four 'Domains of Specialization' (DS) [...] (first column), themselves articulated in 'Themes' (T) (second column) and their relative 'Theme Aims' (TA) (third column). [...] Later, a qualitative evaluation between 'Themes', through their expressions and keywords, and the four 'Sustainable Principles' (SP) was carried out. [...] the four principles are: the 'ethic value' (SP1), the 'knowledge factor' (SP2), the 'environmental respect' (SP3), 'the participation' (SP4), (fourth column).
\end{abstract}

From this description, authors also show the outlines with which it has been possible to trace new themes and design strategies for the new EDS discipline (Di Bucchianico et al., 2012c):

[...] This evaluation, has allowed to generate some 'New Themes' (NT) of 'Ergonomics for Sustainability' as a result of interpolation between the 'Theme Aims' (TA), that represents one of the Ergonomic thematic goals, and the 'Main Principle' (MP) and some possible 'Adjunct Principles' (AP).

Finally [...] the use of AP has permitted to extend the meanings of New Themes, in order to seek a greater adherence to the meaning of Sustainability.

From the systematization of notions, definitions and themes of Ergonomic Design discipline, the tool proposes an its development in the way of SD. Accordingly, considering that the tool follows a similar aim with the one needed by this study, it is crucial to understanding the elements to be modified for the evolution toward the HCD and the SI scopes.

On the basis of existing literature, the process of adaptation can be done following two early premises.

The first premise concerns the thematic analogies that allowed to create the tool for EDS and the one that this study tries to propose. As reported by Marano et al. (2012), the EDS tool was created assuming the hypothesis that disciplines already oriented to SD followed the same process of evolution; then, it is possible to assume as 
a pre-condition that both SD and SI can evolve their conceptual foundations following a similar approach. Two additional deductions support this first premise:

- Both studies have the same nature and almost the same goals. From the development of relevant disciplines they aim to identify new theoretical scenarios. In this study, there is the hypothesis that many disciplines and design issues don't meet the idea of SI so far, but considering that other disciplines already work in this way, it is possible to presume that they can follow the same process.

- SI and SD pursue an analogous conceptual aim. Being SD and SI both 'goaloriented approaches' it is possible to consider, as a hypothesis for the tool generation, that both can act in a very close manner. In other words, it is reasonable to think that because it was possible to create some 'sustainable' disciplines, it is also possible to create 'inclusive' ones following an equivalent development process.

Considering these deductions as preconditions, the early multidisciplinary preverification can be assumed as verified.

For the second premise, it is necessary to understand the reasons that allowed the creation of EDS tool; as said it allows to identify design strategies and themes for Ergonomic Design oriented to SD. But from the analysis of achieved results and considering also the wide nature of the Ergonomics discipline, both strategies and themes have an extremely transversal and generalist connotation compared to the field of Design, on which the tool tries to work; they appear mainly oriented toward the strategic side of SD, than on the design one. The reasons of these results can be found assessing the 'sustainable principles' used as parameters of development, which work 
on a level too intellectual if compared to the design dimension; as a consequence, the nature of results follow a generalist level of definition.

In this phase, a radical change is needed: the principles of SD must be changed with new ones resulting from the combination of HCD and SI (Figure 3), because they can bring a new level of detail on the design dimension. Excluding the part containing the HCD and SI principles, it is possible to maintain the structure of the EDS tool. As a result of this adaptation process, it will be possible to build all parts composing the new methodological tool, which will be called as 'Human-Social Design Tool' (HSDT).

Figure 3 about here

\subsection{Development of human-centred inclusive-oriented design principles}

The review of literature concerning inclusive-oriented design applications shows an intrinsic contradiction on the relations between the theoretical foundations of the approach itself and the design samples composing the totality of case studies (e.g., state of the art). While there are a large number of samples (e.g, Mace, et al., 1996; CUD, 2006), there is a lack of basic references on concepts to be followed. Only a fragmented number of studies and documents contain suggestions on the design principles to be used. Among these, the one proposed by DfA Italia (2009) is composed by eight principles; it also is the only one that can be contemplated for this study. Although the list can be considered as the first in the field of design for SI, the nature of notions shows vague links with the area of design; in other words, the list cannot be properly assumed as a list of design principles because the nature of definitions refers to general goals and characteristics that a solution considered as 'inclusive-oriented' should have. In addition, the list is decontextualized and has no links with the various design stages 
composing the development processes: no kind of ideas can be found on how to develop such principles intro design guidelines.

Accordingly, this development phase concerned the implementation of the eight principles with new insights resulting form the combination of HCD and SI studies. The result of this interpolation is the Table 1, which contains the new eight 'Human-Social Design Principles' (HSDPs) and thirty-three 'Human-Social Design Guidelines' (HSDGs), these last ones have been developed to help designers and design researchers to critically understand the principles' aims and, then, to take into account new useful design evidences for identify human-centred inclusive-oriented strategic and design themes. Furthermore, the new design principles can be considered as insights for the development of promising design strategies, and the specific design guidelines can be intended as effective design themes able to steer and boost the design processes using holistic ideas combining HCD and SI. In this way, it is possible to act both for specific design (micro-level) and for strategic (macro-level) issues, extending the value and the applicability of this framework even for non-design subjects.

Table 1 about here.

\subsection{HSDT development}

Four parts compose the 'Human-Social Design Tool' (HSDT), which describe a logic path exemplified by a table.

The first part (Figure 4) contains the 'Subject Area' (SA), which is the domain where the analysis and the development in the way of HCD and SI should occur. The SA is then divided into three sub-parts characterizing the level of detail for next analyses: 
- The first one refers to the 'Area Themes' (ATs), providing a description about the various specific themes composing the SA.

- The second one contains the 'Theme Aims' (TAs) belonging to each AT: a description on the specific aims composing the considered AT.

- The third one proposes a detailed list of 'Thematic Strategies' (TSs) related to the specific AT that has been taken into account.

Altogether, the first part describes the logical sequence on how to operate a thematic division of the subject to be taken into account for next developments in HCD and SI; from the definitions of theoretical elements (macro-information), the HSDT helps to identify detailed definitions and useful data that will be used in the next operative phases (micro-information).

Figure 4 about here

The second part (Figure 5) contains the eight HSDPs that will be used in the various terminological developments of various TSs in the way of HCD and SI. Blank circles contained in the columns are the HSDGs listed in the Table 1. The main aspect characterizing this second part is that it provides early design suggestions about the aspects that, most than others, will steer the development in the way of HCD and SI; in fact, the combination of TSs with HSDPs will specify, always, a number of 'themes' on which it will be possible to act in the sense of HCD and SI, and on which it will be possible to develop new theoretical notions and design visions.

Figure 5 about here 
The third part (Figure 6) shows the 'New Visions' (NVs) that will be created combining TSs with HSDPs: only those elements considered as promising for the AT taken into account will contribute to address a specific TS in the way of HCD and SI. It is important to note that not all HSDPs can be linked to the TS and, from this condition, it is also possible to present a hierarchical list of valid topics usable by researchers and designers. For each TS, it will be possible to propose a 'Main Vision' (MV) able to address the TS toward a promising aspect of the HCD and SI; later, the other HSDPs taken into account will generate a limited number of 'Adjunct Vision' (AVs), which will be listed as a terminological compendium, completing the development process and the meaning of the proposed MV.

In doing this, two types of specific information will be provided:

- Through the MV, designers and researchers can understand what is the main direction on which it is more correct to develop the TS.

- As a consequence, it is possible to understand the complementary information proposed by AVs that will complete and extend the data already provided through the MV.

Figure 6 about here

Finally, the fourth part collects the results from the previous development phases; the 'Human-Social Design Outcomes' (HSDOs) will refer to the specific SA before considered as an initial parameter interpolation. Figures 7 shows the overall HSDT with all the four parts. 
Figure 7 about here

Considering to the general item ' $a$ ', the following formula shows the various relations proposed by the HSDT:

$$
H S D O_{(a)}=T S_{(a)} \cup N V_{(a)}=T S_{(a)} \cup\left(M V_{(a)} \cap \sum A V_{(a, i)}\right)
$$

Where:

$$
\left\{N V_{(a)} \neq \varnothing \Rightarrow \exists M V_{(a)} \geq 1\right\}
$$

And:

$$
\left\{\begin{array}{c}
\exists i \neq \emptyset \\
\forall \exists i \neq \emptyset: i=T R U E \\
\exists i \in H S D P S \\
0 \leq i \leq 8
\end{array}\right\}
$$

In particular:

- The sentence $\exists M V_{(a)}$ implies that $M V$ always exists; in other words, to develop a given $T S$, it is necessary a single $H S D G$ to be considered as a part of $M V$. Then: $|H S D P| \geq 1$ always.

- The sentence $\forall \exists i \neq \emptyset: i=T R U E$ demonstrates that the maximum number of summable elements, considered as adjunct principles, exist and they are not repeated.

- The sentence $\exists i \in H S D G$ s states that all elements ' $i$ ' inevitably belong to HSDPs. In other words, external factors, data and notions not belonging to $H S D P s$, and then to HSDGs, cannot be considered for the correct development in the way of HCD and SI. 
- Finally, the sentence $0 \leq 1 \leq 8$ states that ' $i$ ' ranges from 0 (there are not $A V s$ ) to 8 (all HSDPS have been considered); it also considers the one used for $M V$, namely: $0 \leq i \leq|H S D G s|$.

\subsection{HSDT functioning}

According to the description of all elements composing the HSDT, it is useful provide a synthetic description of how it can be used. The aim is to show all basic and specific actions that designers and researchers have to consider to achieve 'Human-Social Design Outcomes' (HSDOs) (Figures 8 and 9).

In the first stage, the initial action to be performed concerns the division of elements composing a given SA. In a first time, the SA division generates specific ATs and, later, other two elements are introduced: the TAs, related to the AT, and some TSs strictly linked to each TA. On the whole, these elements describe a hierarchical framework related to the SA, where all data are collected in the three columns, which compose the first part of the HSDT. A strong attention should be given to this early operation of thematic division, because it will determine the overall quality and the grade of accuracy of the conceptual development in the way of HCD and SI.

In the second stage, the HSDPs are combined with the TSs. As it has been discussed, each HSDP qualitatively improves the meanings expressed by all TSs using HSDGs: in this phase it is also possible to understand what are the elements that, more than others, can be considered as innovation drivers to pursue the aims of HCD and SI. This aspect reveals an important relation: not all the HSDPs can be applied to the considered TS, because there will be some HSDPs that more than others will increase the meaning of each TS's sentence. Therefore, the columns containing the HSDPs will show only those HSDGs considered as really applicable to the overall TA's 
improvement and, then, only those taken into account will be considered as the best HSDPs for that specific TA.

In the third stage, the HSDPs will allow to identify the NVs: a number of useful methodological and terminological advances composed by a MV and some AVs. In particular, the MV suggests the main trajectory to successfully develop the TA, having a high grade of certainty that such new insight will be adherent to HCD and SI. On the other hand, the AVs will complete and extend the design meaning already expressed in the MV.

Finally, the last stage collects the HSDOs: the synthesis of the definitions resulting from the interpolation of TS with the data collected by MV and AVs.

Figure 8 about here.

Figure 9 about here.

\section{Testing HSDT in design and non-design disciplines}

The HSDT has been experimentally tested in two different case studies concerning both design and non-design disciplines ${ }^{2}$. Specifically, it has been tested in the field of Interaction Design - as design area - to develop new design guidelines composing a new protocol for Inclusive Natural User Interfaces (INUIs), and in the field of Knowledge Management - as non-design area - to develop original design strategies for

\footnotetext{
${ }^{2}$ Both tests are part of an original research entitled '[name deleted to maintain the integrity of the review process]' conducted by [name deleted to maintain the integrity of the review process], where the HSDT has been developed in its beta version ([name deleted to maintain the integrity of the review process]).
} 
a new interdisciplinary design protocol useful to create knowledge-driven communicative solutions.

\subsection{HSDT in Interaction Design}

A recent design topic for Interaction Design concerns the development of Natural User Interfaces (NUIs) (e.g., Blake, 2011; Wigdor and Wixon, 2011), new types of user interfaces where the interaction model is largely based on the use of gesture-based communication (e.g., gesture-recognition, air-gesture, touches on screen, etc.) (Harper et al., 2008). But NUIs are still based on the idea of standard end-users and solutions are not conceived to meet the real end-users' needs. For example, gestures don't follow real desires of people, visual communication doesn't follow the needs of people with cognitive and visual disabilities, etc. (Rossi, 2014). In order to meet the needs of all possible real end-users, the study developed an early idea of Inclusive Natural User Interface (INUI). Therefore, the HSDT tool has been used to improve a set of new design guidelines previously developed, with the aim to create a more holistic set of inclusive-oriented design guidelines (Figure 10).

Figure 10 about here

The quality of terminological and conceptual improvements resulting from the use of the tool can be seen comparing the extended definitions listed in Table 2 before and after the tool use, where all new concepts have been highlighted and described in detail.

Table 2 about here 
It can be noted that the HSDT was able to introduce new relevant conceptual notions, enriching the development of advanced solutions with new HCD-based and SI-oriented insights. To be more precise, for what concern HCD, the tool exhorts researchers and designers to adopt a more participative approach ('aware') considering end-users throughout all phases related to the development of the solution to be created. This, in fact, is precisely in line with what suggested by ISO (2010) in the principles a), b) and e) of HCD, as listed below:

- The design is based upon an explicit understanding of users, tasks and environments.

- Users are involved throughout design and development.

- The design addresses the whole user experience.

Referring to the dimension of SI, it is possible to see that term 'gratifying' introduce the complete and pleasant satisfaction of end-users during the use of the solution. The idea here sustained is to give enjoyment and pleasantness beyond the usability; in fact, the satisfaction is, from the psychological point of view, an emotional characteristic involving happiness, joy, empowerment and valorisation of personal attitudes (e.g. abilities) in the pursuing of a goal. Moreover, the term 'gratifying' is also connected with the domain of Human Factors, linking one of the three pillar composing the definition of usability: the satisfaction of use (ISO 924111, 1998).

\subsection{HSDT in Knowledge Management}

Sharing knowledge is a very complex activity, especially when people want to share their experience and know-how (Polanyi, 1958; 1966). Since 90's, researchers working in the area of the so-called Knowledge Sharing Theory have investigated this topic (e.g., von Krogh, 1998; Foray, 2004; Stevens, 2010) developing some interesting studies to 
describe the processes needed to convert and share tacit knowledge. On this matter, the study proposed by Ikujiro Nonaka $(1991 ; 1994)$ consists in a descriptive method that shows how the knowledge flow can be converted to its tacit form into communicable ones. This method, called as SECI (acronym of Socialization-ExternalizationCombination-Internalization), has been reinterpreted to be applicable in the design of communicative ICT-based solutions.

As a part of a larger study on the role of knowledge sharing-oriented communication tools (Rossi, 2014), a number of new design strategies and early design macro-guidelines have been developed using the HSDT. Combining non-design information and non-design-oriented ideas, the HSDT has allowed to create a very focused set of design-oriented strategies and guidelines, confirming the value of HSDT in a very complex research domain where design experiments have not been conducted yet.

Figure 11 shows the application of HSDT in non-design area and Table 3 shows the different terminological improvements that allowed to evolve early raw strategies into effective human-centred inclusive-oriented design guidelines.

Figure 11 about here

Table 3 about here

Being in principle a non-design topic, this sample introduces a number of new concepts and links for HCD, SI and Human Factors. Accordingly, there is a balance between such disciplines within the new terms 'enable', 'balanced' and 'understandable by all'. 
The term 'enable' comes up from the SI domain, which promotes the empowerment of all end-users and, in Design, aims to the autonomous inclusion and valorisation of people within society through the use of products (e.g. EIDD, 2004). It also is linked with Human Factors and HCD where it is intended as an interpretation of the concept of efficiency, belonging to usability (ISO 9241-11, 1998).

The term 'balanced' is strictly referred to the ergonomic quality of communication, which means the efficiency and the effectiveness of the information provided by the solutions designable from strategy developed in the recalled study. The term also introduces new insights for the SI point of view, promoting the development of solutions able to meet end-users' abilities.

Finally, the term 'understandable by all' can be referred, equally, to Human Factors, HCD and SI, where the grade of understandability of the communication is intended as a mix of proper semantic elements and solutions merging end-users' analysis (Human Factors), involvement of stakeholders in the process of development (HCD) and valorisation and respect of end-users' abilities (SI).

\section{Conclusion}

This study has proposed and discussed a new comprehensive design tool that combines both HCD and SI approaches. It has been developed starting from the need to have at the same time holistic design data able to enhance, both qualitatively and quantitatively, terminological definitions belonging to design and non-design disciplines.

Through a rigorous methodology and using inductive research approaches based on the review of literature, it has been possible to develop and test a new tool called as 'Human-Social Design Tool' (HSDT). On the operative side, the tool is a table divided into four areas, which describe four different methodological processes; from the 
thematic analysis of subjects and specific theoretical themes, the tool can help designers and researchers to develop new design insights belonging to both design and non-design scientific domains. Moreover, the tool has been used during a cross-sectorial study on the issue of 'design for knowledge sharing', allowing to obtain useful data with an high grade of accurateness, increasing the value of the study and developing new humancentred and social inclusion-oriented data.

In brief, the HSDT is an easy-to-use tool useful to identify focused results oriented toward HCD and SI; it is able to develop conceptual and terminological definitions for both design and non-design subjects. Using logical sequences, it shows how to develop given data into new human-centred and social inclusion-oriented records. Furthermore, the tools is able to introduce a number of practical benefits useful for those research issues related to the development of new concepts, including: accuracy of results, intrinsic flexibility, ability to work with design and non-design subjects, usability; from any theoretical definition, it is possible to trace new designoriented conceptual elements to address simultaneously the development of new HCD and SI design strategies and guidelines.

In terms of overall quality, this study presented two important final elements. It has been proved the possibility to create new multidisciplinary links between design research areas that, at the moment, don't pursue the same goals, both for theoretical and for methodological reasons; as it has been discussed, there is the real chance to act in the way of research innovations and, then, new experiments on this view can produce remarkable results. The second consideration concerns the possibility to work within the discipline of Design Research in a new manner; in fact, it has been discussed that using new experimental methodological approaches, it is possible to develop new models and 
tools to explore new research concepts, promoting then the investigations in new multidisciplinary areas not examined at the moment, like those in non-design fields.

Finally, it is possible to consider this work relevant for Human Factors and Ergonomic Design because it has been shown that the HSDT, composed by a mix of notions arising form HCD and SI, introduces, many times, a significant number of elements belonging to Human Factors discipline. Specifically, the new notions introduced by the tool and discussed in the testing phase have shown a clear adherence with the principles and the topics of Human Factors, enriching them with new concepts belonging HCD and SI. This can be intended as a confirmation that Human Factors discipline is fundamental for the good development of HCDbased and/or SI-oriented solutions and, it can be considered as a useful connector for all new studies and applications aiming to create a convergence between HCD and SI.

\section{References}

Accolla, A. 2009. Design for All: Il Progetto per l'Individuo Reale. Milan: Franco Angeli.

Annett, J. 2004. Hierarchical Task Analysis (HTA). In: Handbook of Human Factors and Ergonomics Methods, edited by: Stanton, N., A. Hedge, K. Brookhuis, E. Salas and H. Hendrick, 33-1-33-7. Boca Raton, FL: CRC Press.

Bandini Buti, L. 2008. Ergonomia Olistica: Il Progetto per la Variabilità Umana. Milan: Franco Angeli.

Bazzano, A.N., J. Martin, E. Hicks, M. Faughnan and L. Murphy. 2017. HumanCentred Design in Global Health: A Scoping Review of Applications and Contexts. PLoS ONE, 12 (11), e0186744. doi:

org/10.1371/journal.pone.0186744.

Blake, J. (2011). Natural User Interfaces in .NET. Greenwich, CT: Manning Publications. 
Buchanan, R. 2001. Human Dignity and Human Rights: Thoughts on the Principles of Human-Centered Design. Design issues, 17 (3), 35-39. doi: 10.1162/074793601750357178.

Buckley, B.C., J.D. Gobert, P. Horwitz and L.M. O’Dwyer. 2010. Looking Inside the Black Box: Assessing Model-Based Learning and Inquiry in BioLogica ${ }^{\mathrm{TM}}$. International Journal of Learning Technology 5 (2), 166-190. doi: 10.1504/IJLT.2010.034548.

Cappo, D. 2002. Social Inclusion, Participation and Empowerment. Address to Australian Council of Social Services National Congress 28-29 November, 2002, Hobart.

Center for Universal Design. 2006. The Principles of Universal Design (Press Release). Raleigh, NC: North Carolina State University, Center for Universal Design.

Clarkson, P.J., R. Coleman, S. Keates, S. and C. Lebbon. 2003. Inclusive Design: Design for the Whole Population, London: Springer-Verlag.

\section{Clarkson, P.J. and R. Coleman. 2015. History of Inclusive Design in the UK,} Applied Ergonomics 46 (Part B), 235-247. doi: 10.1016/j.apergo.2013.03.002.

Design for All Italia. 2009. I Marchi DfA (Press Release), Milan: s.d.

Di Bucchianico, G. 2011. "DFA FF” (Design for All Fast Forward): From Design “Approach" to Design "Toolkit”. In: Contemporary Ergonomics and Business 2011: Proceedings of the First International Scientific-Practical Conference of the Latvian Ergonomics Society, 14-20. Riga: University of Latvia Press.

Di Bucchianico, G., M. Gregori and E. Rossi. 2012a; Designing From Activities: The "Ability/Difficulty Table", a Useful Tool to Detect the "Limit Users" in the Design for All Approach. Work, 41 (Supplement 1/2012), 1362-1367. doi: 10.3233/WOR-2012-0325-1362.

Di Bucchianico, G., S. Camplone, S. Picciani and V. Vallese. 2012b. "EWS Matrix" and "EWG Matrix": "De-sign for All" Tools Referred to the Development of a Enabling Communication System for Public Spaces. Work, 41 (Supplement 1/2012), 1368-1373. doi: 10.3233/WOR-2012-0326-1368.

Di Bucchianico, G., A. Marano, E. Rossi and S. Picciani. 2012c. Defining Ergonomic Design for Sustainability Approach: Methodology and First Verification on Usability of Products. In: Proceedings of NES2012 - Ergonomics for Sustainability and Growth, edited by: Antonsson, A-B., K. Vogel, and G.M. 
Hägg, B2:3.11-15. Stockholm: KTH Royal Institute of Technology, School of Technology and Health.

Di Bucchianico, G. 2015. Design for Human Diversity in the Maritime Design Domain. Theoretical Issues in Ergonomics Science, 16 (4), 388-398. doi: 10.1080/1463922X.2015.1014070.

Dong. H. 2009. Strategies for Teaching Inclusive Design. Journal of Engineering Design, 21 (2-3), 237-251. doi: 10.1080/09544820903262330.

EIDD (European Institute for Design and Disability). 2004. The EIDD Stockholm Declaration. Adopted on 9 May 2004 at the Annual General Meeting of the European Institute for Design and Disability in Stockholm.

Follette Story, M., J. Mueller, and Mace, R.L. 1998. The Universal Design File:

Designing for People of All Ages and Abilities. Raleigh, NC: North Carolina State University, Center for Universal Design.

Foray, D. 2004. The Economics of Knowledge. Cambridge, MA: The MIT Press. Giacomin, J. 2015. What Is Human Centred Design? The Design Journal 17 (4), 606623. doi: 10.2752/175630614X14056185480186.

Goodman-Deane, J., J. Ward, I. Hosking and J.P. Clarkson. 2014. A Comparison of Methods Currently Used in Inclusive Design. Applied Ergonomics 45 (4), 886-894. doi: 10.1016/j.apergo.2013.11.005.

Harper, R., T. Rodden, Y. Rogers and A. Sellen. 2008. Being Human: HumanComputer Interaction in the Year 2020. Cambridge: Microsoft Research Ltd.

ISO (International Organization for Standardization). 1998. Ergonomic Requirements for Office Work with Visual Display Terminals (VDTs) -- Part 11: Guidance on Usability (ISO 9241-11:1998). Geneva: Switzerland. ISO (International Organization for Standardization). 2010. Ergonomics of Human-System Interaction - Part 210: Human-Centred Design for Interactive Systems (ISO 9241-210). Geneva: Switzerland.

Keates S. and P.J. Clarkson 2002. Defining Design Exclusion: Universal Access And Assistive Technology, London: Springer-Verlag.

Kothari C.R. and G. Garg, 2014. Research Methodology : Methods and Techniques. New Delhi: New Age International.

Krippendorff, K. 2007. Intrinsic Motivation and Human-Centred Design. Theoretical Issues in Ergonomics Science, 5 (1), 43-72. doi: 10.1080/1463922031000086717. 
Lofthouse, V. and S. Prendeville. 2018. Human-Centred Design of Products and Services for the Circular Economy: A Review. The Design Journal, 1-26 doi: 10.1080/14606925.2018.1468169.

Mace, R.L., G.J. Hardie, and J.P. Place. 1996. Accessible Environments: Toward Universal Design. Raleigh, NC: North Carolina State University, Center for Universal Design.

Maguire, M. 2001. Methods to Support Human-Centred Design. International Journal of Human-Computer Studies 55 (4), 587-634. doi:

https://doi.org/10.1006/ijhc.2001.0503.

Manzini, E. 2007a. Design, Social Innovation and Sustainable Ways of Living. Milan: DIS Indaco.

Manzini, E. 2007b. Design Research for Sustainable Social Innovation. In: Design Research Now: Essays and Selected Projects, edited by: Ralf, M., 233-245. Basel: Birkhauser.

Marano, A., Di Bucchianico, G. and Rossi, E. 2012. Strategies and Arguments of Ergonomic Design for Sustainability. WORK 41 (Supplement 1/2012), 38693873. doi: 10.3233/WOR-2012-0053-3869.

Nielsen, J. 1994. Heuristic Evaluation. In: Usability Inspection Methods, edited by: Nielsen, J., and R.L. Mack, 25-62. New York, NY: John Wiley \& Sons.

Nonaka, I. 1991. The Knowledge-Creating Company. Harvard Business Review 69, Nov-Dec., 96-104. url: https://hbr.org/2007/07/the-knowledge-creatingcompany.

Nonaka, I. (1994). A Dynamic Theory of Organizational Knowledge Creation. Organization Science, 5 (2), 14-37. doi: 10.1287/orsc.5.1.14.

Nowak, E. 1996. The role of anthropometry in design of work and life environments of the disabled population. International Journal of Industrial Ergonomics 17 (2), 113-121. doi: https://doi.org/10.1016/0169-8141(95)00043-7.

Ornelas, Y. and J. Gregory. 2009. Design for Social Inclusion, In: Proceedings of IASDR 2009: Design, Rigor \& Relevance. s.1.: The Design Society, 4529-4533.

Pheasant S. and C.M. Haslegrave. 2005. Bodyspace: Anthropometry, Ergonomics and the Design of Work ( $3^{r d}$ Edition). Boca Raton, FL: CRC Press.

Polanyi, M. 1958. Personal Knowledge: Towards a Post-Critical Philosophy. Chicago, IL: University Of Chicago Press.

Polanyi, M. .1966. The Tacit Dimension. London: Routledge. 
Rossi, E. and P. Barcarolo. 2013. Enhancing human diversities through the design for all approach: Potentialities and relevant issues for emerging countries. In: Proceedings of the Gaborone International Design Conference (GIDEC) 2013: Design Future: Creativity, Innovation and Development, (digital). Gabrone: University of Botswana.

Rossi, E. 2014. Designing Inclusive Natural User Interfaces for Sharing Know-How. $\mathrm{PhD}$ dissertation, University of Chieti-Pescara, Italy.

Rossi, E. and P. Barcarolo. 2015. A Multidisciplinary Design Approach to Enhance the Use and the Enjoyment of Museums, Cultural and Natural Heritage. In: Proceedings of INSIGHT 2015 Design Research Symposium, (digital). Bangalore: National Institute of Design.

Stanton, N.A. 2006 Hierarchical task analysis: developments, applications, and extensions. Applied Ergonomics 37 (1), 55-79. doi: https://doi.org/10.1016/j.apergo.2005.06.003.

Steen, M. 2011. Tensions in Human-Centred Design. CoDesign, 7 (1), 45-60. doi: $10.1080 / 15710882.2011 .563314$.

Stevens, R.H. 2010. Managing Human Capital: How to Use Knowledge Management to Transfer Knowledge in Today's Multi-Generational Workforce. International Business Research 3 (7), 77-83. doi: 10.5539/ibr.v3n3p77.

Verganti, R. 2008. Design, Meanings and Radical Innovation: A Research Agenda. Journal of Product Innovation Management, 25 (5), 436-456. doi:10.1111/j.1540-5885.2008.00313.x.

von Krogh, G. 1998. Care in Knowledge Creation. California Management Review, 40 (3), 133-153. doi: https://doi.org/10.2307/41165947.

Welch, P. 1995. Strategies for Teaching Universal Design. Berkeley, CA: Mig Communications.

Wigdor, D. and D. Wixon. 2011. Brave NUI World: Designing Natural User Interfaces for Touch and Gesture. Burlington, MA: Morgan Kaufmann. 
Figure 1. The 'black box condition' shows intrinsic lacks related to the development of human-centred and inclusive-oriented records.

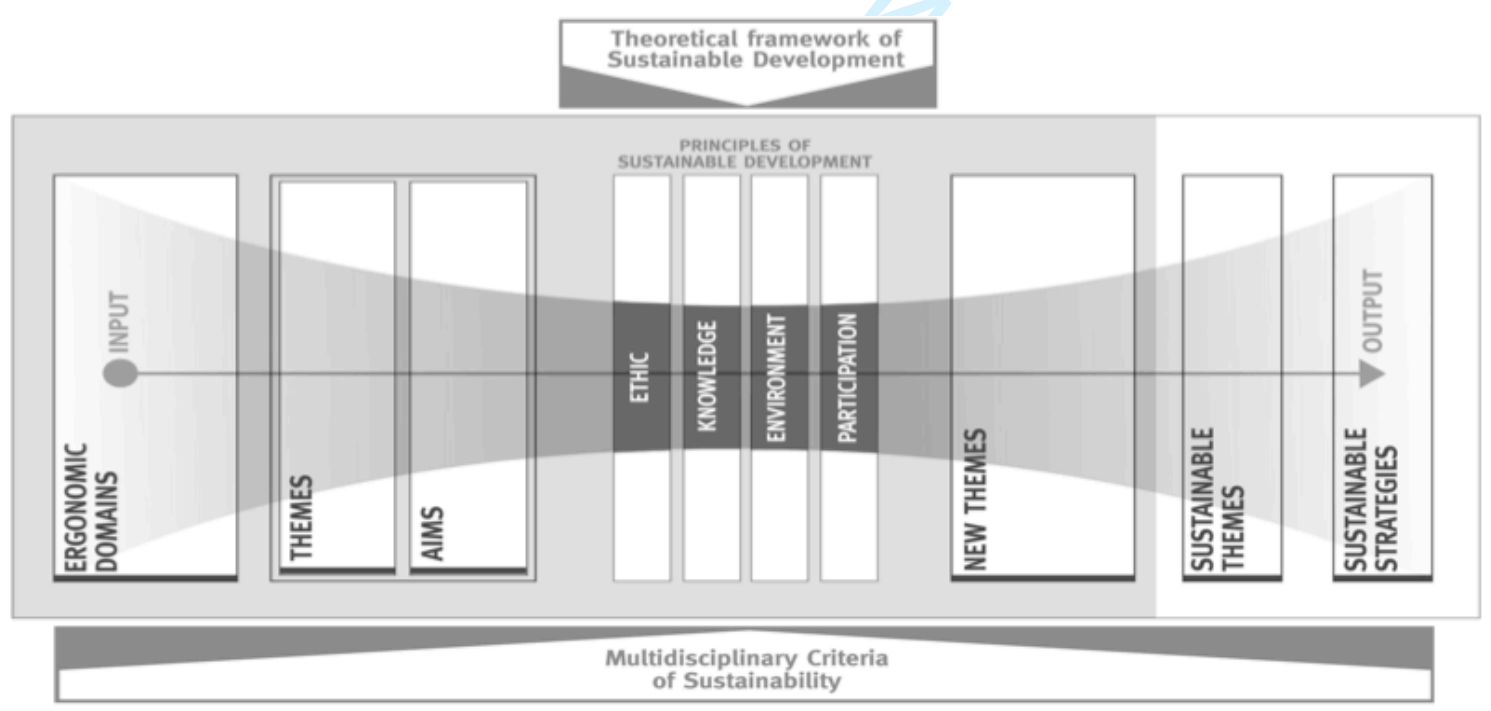

Figure 2. The QLR tool used in the development of Ergonomic Design for Sustainability (EDS) data (Marano et al., 2012). 

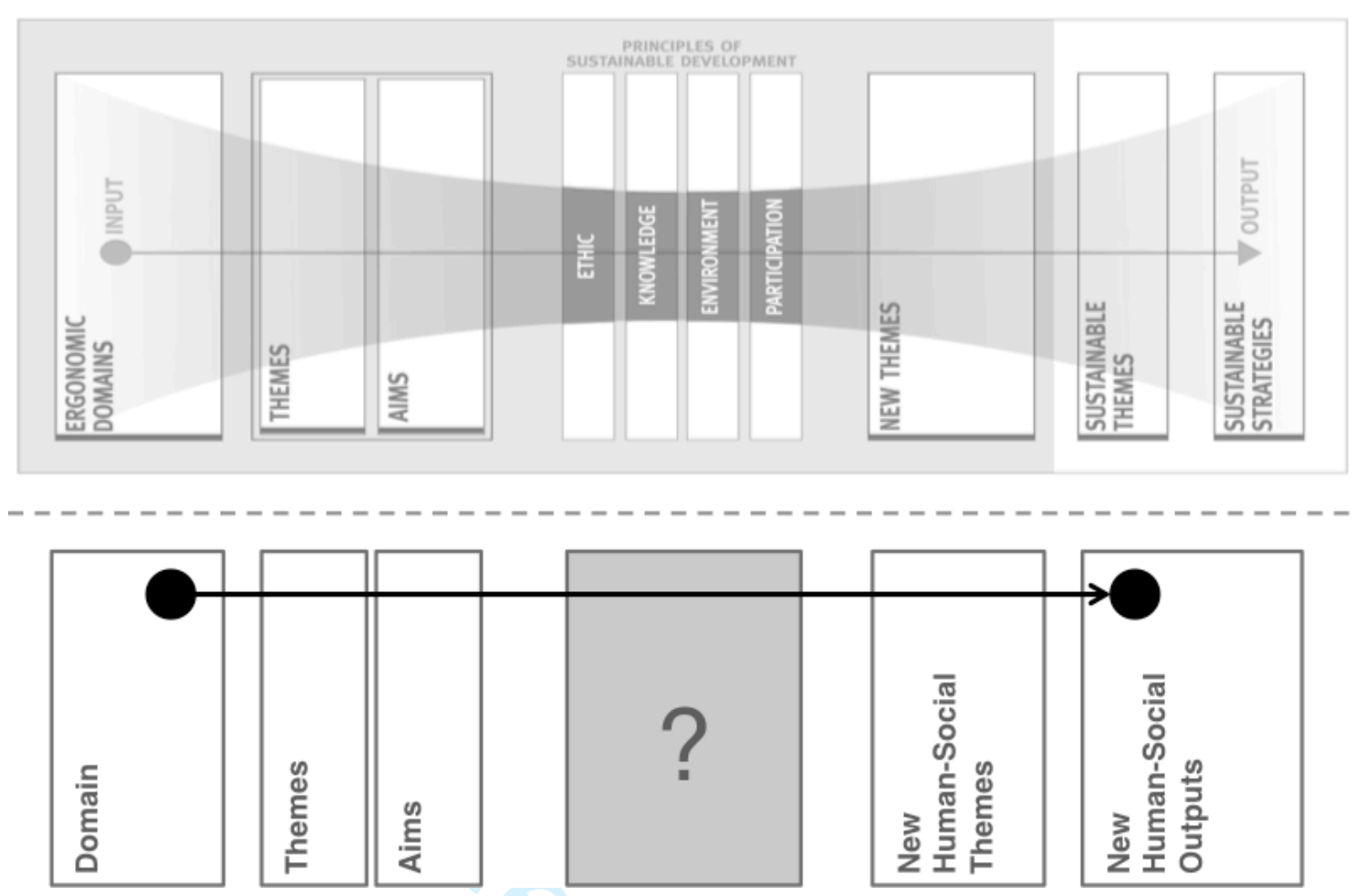

Figure 3. Conceptual and methodological evolution from EDS to HCD and SI.

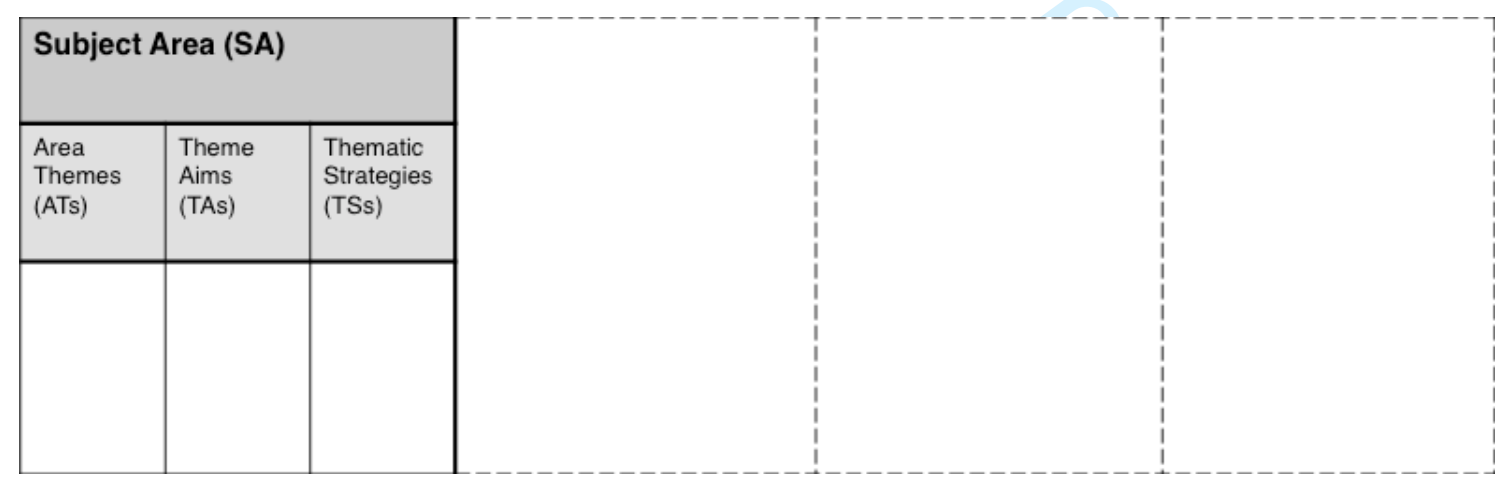

Figure 4. The first part composing the HSDT containing the 'Subject Area' (SA), the 'Area Themes' (ATs), the 'Theme Aims' (TAs) and the 'Thematic Strategies' (TSs). 


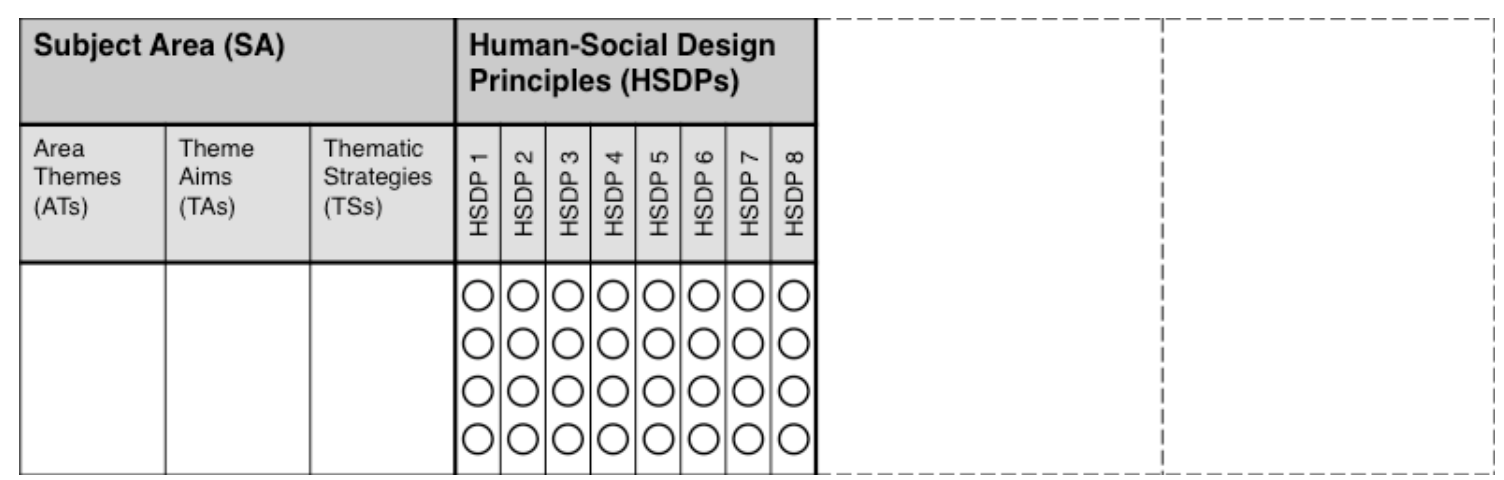

Figure 5. The second part composing the HSDT containing the eight 'Human-Social Design Principles' (HSDPs) and related 'Human-Social Design Guidelines' (HSDGs).

\begin{tabular}{|c|c|c|c|c|c|c|c|c|c|}
\hline \multicolumn{3}{|c|}{ Subject Area (SA) } & \multicolumn{5}{|c|}{\begin{tabular}{|l|} 
Human-Social Design \\
Principles (HSDPs)
\end{tabular}} & \multicolumn{2}{|c|}{ New Visions (NVs) } \\
\hline \multirow[t]{2}{*}{$\begin{array}{l}\begin{array}{l}\text { Area } \\
\text { Themes } \\
\text { (ATs) }\end{array} \\
\end{array}$} & $\begin{array}{l}\text { Theme } \\
\text { Aims } \\
\text { (TAs) }\end{array}$ & $\begin{array}{l}\text { Thematic } \\
\text { Strategies } \\
\text { (TSs) }\end{array}$ & 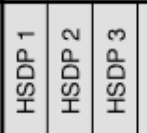 & \begin{tabular}{l|l} 
\\
0 \\
0 \\
0 \\
S
\end{tabular} & $\begin{array}{l}0 \\
0 \\
0 \\
0 \\
1 \\
\end{array}$ & \begin{tabular}{l|}
0 \\
0 \\
0 \\
0 \\
$\underline{0}$
\end{tabular} & 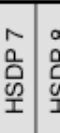 & $\begin{array}{l}\text { Main Vision } \\
\text { (MV) }\end{array}$ & \begin{tabular}{|l} 
Adjunct \\
Visions \\
(AVs)
\end{tabular} \\
\hline & & & $\begin{array}{lll}0 & 0 & 0 \\
0 & 0 & 0 \\
0 & 0 & 0 \\
0 & 0 & 0\end{array} \mid$ & C & & 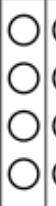 & 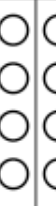 & & \\
\hline
\end{tabular}

Figure 6. The third part composing the HSDT containing the 'New Visions' (NVs), the 'Main Vision' (MV) and the 'Adjunct Visions' (AVs). 


\begin{tabular}{|c|c|c|c|c|c|c|c|c|c|c|c|c|}
\hline \multicolumn{3}{|c|}{ Subject Area (SA) } & \multicolumn{7}{|c|}{$\begin{array}{l}\text { Human-Social Design } \\
\text { Principles (HSDPs) }\end{array}$} & \multicolumn{2}{|c|}{ New Visions (NVs) } & \multirow{2}{*}{$\begin{array}{l}\text { Human-Social } \\
\text { Design Outcomes } \\
\text { (HSDOs) }\end{array}$} \\
\hline $\begin{array}{l}\text { Area } \\
\text { Themes } \\
\text { (ATs) }\end{array}$ & $\begin{array}{l}\text { Theme } \\
\text { Aims } \\
\text { (TAs) }\end{array}$ & $\begin{array}{l}\text { Thematic } \\
\text { Strategies } \\
\text { (TSs) }\end{array}$ & $\begin{array}{l}- \\
0 \\
0 \\
00 \\
0 \\
0\end{array}$ & $\begin{array}{l}\text { N } \\
0 \\
0 \\
0 \\
0\end{array}$ & $\begin{array}{l}\text { m } \\
0 \\
0 \\
0 \\
\text { I }\end{array}$ & 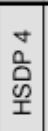 & $\begin{array}{l}n \\
0 \\
0 \\
0 \\
\text { I }\end{array}$ & 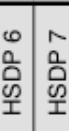 & $\begin{array}{l}\infty \\
0 \\
0 \\
0 \\
0 \\
0\end{array}$ & $\begin{array}{l}\text { Main Vision } \\
\text { (MV) }\end{array}$ & $\begin{array}{l}\text { Adjunct } \\
\text { Visions } \\
\text { (AVs) }\end{array}$ & \\
\hline & & & & & & & م & & & & & \\
\hline
\end{tabular}

Figure 7. HSDT: overall scheme.

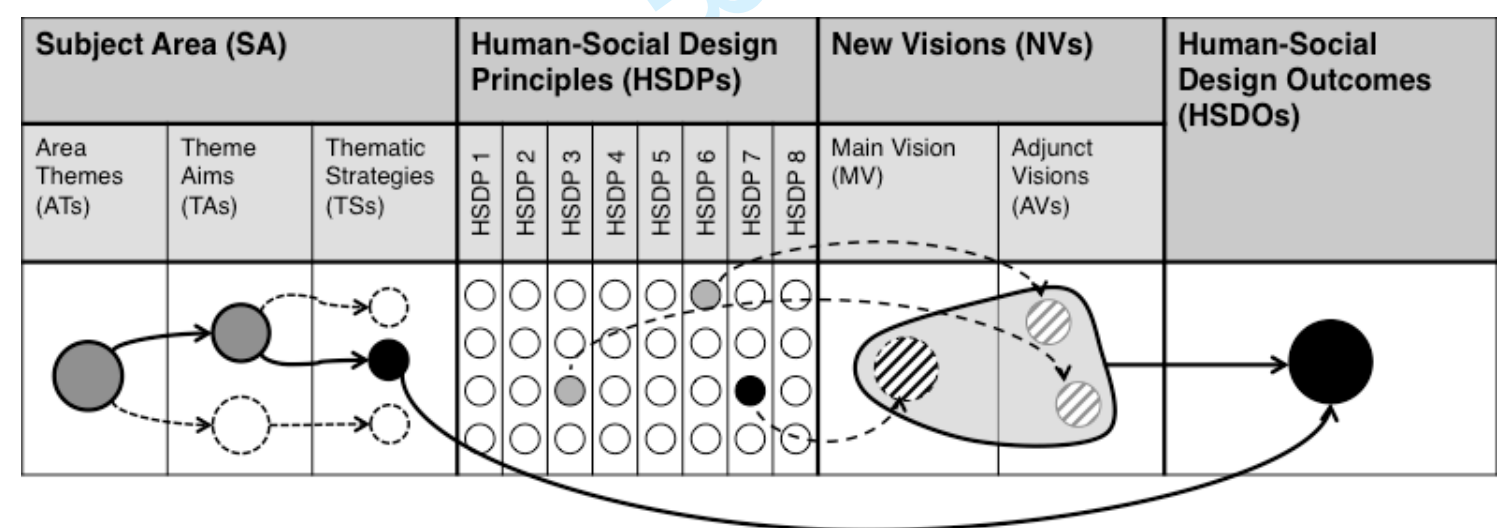

Figure 8. HSDT functioning. 


\begin{tabular}{|c|c|c|c|c|c|c|c|c|c|c|c|c|c|}
\hline \multicolumn{3}{|c|}{ Subject Area (SA) } & \multicolumn{8}{|c|}{$\begin{array}{l}\text { Human-Social Design } \\
\text { Principles (HSDPs) }\end{array}$} & \multicolumn{2}{|c|}{ New Visions (NVs) } & \multirow{2}{*}{$\begin{array}{l}\text { Human-Social } \\
\text { Design Outcomes } \\
\text { (HSDOs) }\end{array}$} \\
\hline $\begin{array}{l}\text { Area } \\
\text { Themes } \\
\text { (ATs) }\end{array}$ & $\begin{array}{l}\text { Theme } \\
\text { Aims } \\
\text { (TAs) }\end{array}$ & $\begin{array}{l}\text { Thematic } \\
\text { Strategies } \\
\text { (TSs) }\end{array}$ & & \begin{tabular}{l|}
$\sim$ \\
0 \\
0 \\
0 \\
I
\end{tabular} & $\begin{array}{l}m \\
0 \\
0 \\
0 \\
\text { T⿱一土 }\end{array}$ & 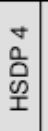 & $\begin{array}{l}n \\
0 \\
0 \\
0 \\
\frac{0}{1}\end{array}$ & \begin{tabular}{|l|} 
\\
0 \\
0 \\
00 \\
0 \\
1
\end{tabular} & $\begin{array}{l}\hat{n} \\
0 \\
0 \\
0 \\
\text { I }\end{array}$ & $\begin{array}{l}\infty \\
0 \\
0 \\
0 \\
\\
\end{array}$ & $\begin{array}{l}\text { Main Vision } \\
\text { (MV) }\end{array}$ & $\begin{array}{l}\text { Adjunct } \\
\text { Visions } \\
\text { (AVs) }\end{array}$ & \\
\hline \multirow{3}{*}{ AT } & \multirow[t]{2}{*}{$\mathrm{TA}_{(1)}$} & $\mathrm{TS}_{(1,1)}$ & $\left|\begin{array}{l}0 \\
0 \\
0 \\
0\end{array}\right|$ & $\bigcirc$ & 0 & $\bigcirc$ & $\bigcirc$ & $\begin{array}{l}0 \\
\mathrm{O}\end{array}$ & $\begin{array}{l}\bigcirc \\
\bigcirc \\
\bigcirc \\
\bigcirc\end{array}$ & $\begin{array}{l}0 \\
0 \\
0 \\
0\end{array}$ & $\mathrm{MV}_{(2,2)}$ & $\begin{array}{l}\operatorname{AV}_{(5,2)} \\
\operatorname{AV}_{(6,4)}\end{array}$ & $\begin{array}{l}\mathrm{TS}_{(1,2)} \mathrm{U}\left[\mathrm{MV}_{(2,2)} \cap\right. \\
\left.\left(\mathrm{AV}_{(5,2)}+\mathrm{AV}_{(6,4)}\right)\right]\end{array}$ \\
\hline & & $\mathrm{TS}_{(1,2)}$ & & & & & & & & & $\cdots$ & $\cdots$ & $\cdots$ \\
\hline & $\mathrm{TA}_{(2)}$ & $\mathrm{TS}_{(2,1)}$ & & & & & & & & & $\cdots$ & $\cdots$ & $\cdots$ \\
\hline & & & & & & & & & & & & & $\checkmark$ \\
\hline
\end{tabular}

Figure 9. Development of Human-Social Design Outcomes (HSDOs) from the generic item $\operatorname{TS}_{(1,1)}$.

\begin{tabular}{|c|c|c|c|c|c|c|c|c|c|c|c|c|c|}
\hline \multicolumn{3}{|c|}{ Subject Area (SA) } & \multicolumn{8}{|c|}{$\begin{array}{l}\text { Human-Social Design } \\
\text { Principles (HSDPs) }\end{array}$} & \multicolumn{2}{|c|}{ New Visions (NVs) } & \multirow{2}{*}{$\begin{array}{l}\text { Human-Social } \\
\text { Design Outcomes } \\
\text { (HSDOs) }\end{array}$} \\
\hline $\begin{array}{l}\text { Area } \\
\text { Themes } \\
\text { (ATs) }\end{array}$ & $\begin{array}{l}\text { Theme } \\
\text { Aims } \\
\text { (TAs) }\end{array}$ & $\begin{array}{l}\text { Thematic } \\
\text { Strategies } \\
\text { (TSs) }\end{array}$ & $\mid \begin{array}{l}- \\
\frac{-}{2} \\
0 \\
0 \\
1\end{array}$ & $\begin{array}{l}\infty \\
0 \\
0 \\
0 \\
0 \\
\text { I }\end{array}$ & $\begin{array}{l}m \\
0 \\
0 \\
0 \\
\text { 1 }\end{array}$ & $\begin{array}{l}+ \\
0 \\
0 \\
00 \\
\text { Tे } \\
\end{array}$ & $\begin{array}{l}n \\
0 \\
0 \\
00 \\
\text { I }\end{array}$ & $\begin{array}{l}0 \\
0 \\
0 \\
0 \\
\frac{0}{1}\end{array}$ & $\begin{array}{l}\hat{n} \\
0 \\
0 \\
0 \\
\text { I }\end{array}$ & $\begin{array}{l}\infty \\
0 \\
0 \\
0 \\
0\end{array}$ & $\begin{array}{l}\text { Main Vision } \\
\text { (MV) }\end{array}$ & $\begin{array}{l}\text { Adjunct } \\
\text { Visions } \\
\text { (AVs) }\end{array}$ & \\
\hline NUI Design & $\begin{array}{l}\text { Human- } \\
\text { Machine } \\
\text { Comm. } \\
\text { (HMC) }\end{array}$ & $\begin{array}{l}\text { Allow the } \\
\text { continuous } \\
\text { gestures' } \\
\text { self- } \\
\text { learning }\end{array}$ & C & & & & & & & & $\begin{array}{l}\text { Empower the } \\
\text { personal } \\
\text { satisfaction }\end{array}$ & $\begin{array}{l}\text { Aware use of } \\
\text { services } \\
\text { Adaptation to } \\
\text { the } \\
\text { expectations } \\
\text { of end-users }\end{array}$ & $\begin{array}{l}\text { Allow the continuous, aware } \\
\text { and gratifying gestures' self- } \\
\text { learning }\end{array}$ \\
\hline
\end{tabular}

Figure 10. HSDT application in Interaction Design domain. 


\begin{tabular}{|c|c|c|c|c|c|c|c|c|c|c|c|c|c|}
\hline \multicolumn{3}{|c|}{ Subject Area (SA) } & \multicolumn{8}{|c|}{$\begin{array}{l}\text { Human-Social Design } \\
\text { Principles (HSDPs) }\end{array}$} & \multicolumn{2}{|c|}{ New Visions (NVs) } & \multirow{2}{*}{$\begin{array}{l}\text { Human-Social } \\
\text { Design Outcomes } \\
\text { (HSDOs) }\end{array}$} \\
\hline $\begin{array}{l}\text { Area } \\
\text { Themes } \\
\text { (ATs) }\end{array}$ & $\begin{array}{l}\text { Theme } \\
\text { Aims } \\
\text { (TAs) }\end{array}$ & $\begin{array}{l}\text { Thematic } \\
\text { Strategies } \\
\text { (TSs) }\end{array}$ & $\begin{array}{l}- \\
0 \\
0 \\
0 \\
\text { I }\end{array}$ & $\begin{array}{l}\sim \\
0 \\
0 \\
00 \\
\text { I }\end{array}$ & $\begin{array}{l}0 \\
0 \\
0 \\
00 \\
\frac{0}{1}\end{array}$ & $\begin{array}{l}+ \\
0 \\
0 \\
0 \\
\frac{0}{1}\end{array}$ & $\begin{array}{l}0 \\
0 \\
0 \\
0 \\
1 \\
\end{array}$ & \begin{tabular}{|l|}
0 \\
0 \\
0 \\
00 \\
1
\end{tabular} & $\begin{array}{l}n \\
0 \\
0 \\
0 \\
0 \\
\end{array}$ & $\begin{array}{l}\infty \\
0 \\
00 \\
0 \\
1\end{array}$ & $\begin{array}{l}\text { Main Vision } \\
\text { (MV) }\end{array}$ & \begin{tabular}{|l} 
Adjunct \\
Visions \\
(AVs)
\end{tabular} & \\
\hline Socializ. & \begin{tabular}{|l} 
Tacit \\
Knowledge \\
Sharing
\end{tabular} & $\begin{array}{l}\text { Represent } \\
\text { and } \\
\text { detailing } \\
\text { existing } \\
\text { tacit } \\
\text { knowledge, } \\
\text { including its } \\
\text { themes and } \\
\text { aims }\end{array}$ & C & & & & & & & C & $\begin{array}{l}\text { Solutions } \\
\text { adequate to } \\
\text { the personal } \\
\text { capabilities }\end{array}$ & 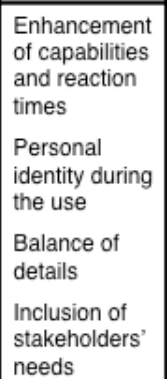 & $\begin{array}{l}\text { Enable stakeholders to } \\
\text { represent and detail existing } \\
\text { tacit knowledge, including its } \\
\text { themes and aims, through } \\
\text { balanced communicative } \\
\text { forms really understandable } \\
\text { by all }\end{array}$ \\
\hline
\end{tabular}

Figure 11. HSDT application in Knowledge Management domain. 
Table 1. Human-Social Design Principles (HSDPs) (left) and Human-Social Design Guidelines (HSDGs) (right).

\begin{tabular}{|c|c|}
\hline $\begin{array}{l}\text { Human-Social Design Principles } \\
\text { (HSDPs) }\end{array}$ & Human-Social Design Guidelines (HSDGs) \\
\hline 1. Valorise human diversity. & $\begin{array}{l}\text { 1.1. Enhance end-users' ethnic-anthropometric } \\
\text { characteristics. } \\
\text { 1.2. Enhance end-users' psycho-cognitive and } \\
\text { interpretative-cultural capabilities. } \\
\text { 1.3. Enable end-users' physical conditions, } \\
\text { handicaps and disabilities (even temporary ones). } \\
\text { 1.4. Empower end-users' diversified capabilities and } \\
\text { times of reaction to external stimuli. }\end{array}$ \\
\hline $\begin{array}{l}\text { 2. Promote Social Inclusion and } \\
\text { equality. }\end{array}$ & $\begin{array}{l}\text { 2.1. Support the access and the use of services and } \\
\text { existing solutions in an aware and responsible way. } \\
\text { 2.2. Support in a synergic way the interaction and the } \\
\text { participation of stakeholders to their most } \\
\text { appropriate level. } \\
\text { 2.3. Promote the cooperation, the socialization and } \\
\text { the establishment of networks among stakeholders in } \\
\text { order to optimize and rationalize the access to } \\
\text { resources. } \\
\text { 2.4. Support the personal identity, the homogeneity } \\
\text { and the equity in the autonomous fruition, even } \\
\text { during collective interventions. }\end{array}$ \\
\hline 3. Make easy and pleasant the & 3.1. Give the chance to easily choose and enjoy the \\
\hline
\end{tabular}




\begin{tabular}{|c|c|}
\hline use for all possible end-users. & $\begin{array}{l}\text { most easy and pleasant technically adequate and } \\
\text { suitable solutions. } \\
\text { 3.2. Give the chance to easily choose the most all- } \\
\text { inclusive, tolerant and psychophysically adaptive } \\
\text { solutions. } \\
\text { 3.3. Foster the choose of pleasant, playful and } \\
\text { reversible solutions. } \\
\text { 3.4. Make the fruition suitable to the evolution of } \\
\text { aesthetic trends, cultures and end-users' personal } \\
\text { aspirations and needs. }\end{array}$ \\
\hline $\begin{array}{l}\text { 4. Avoid psychological and } \\
\text { physical stigmas. }\end{array}$ & $\begin{array}{l}\text { 4.1. Admit in advance and in an inclusive way } \\
\text { conducts and personal choices deriving from } \\
\text { cognitive-behavioral and socio-cultural activities. } \\
\text { 4.2. Admit in advance and in an inclusive way } \\
\text { interpretative diversities, learning attitudes, errors, } \\
\text { ambiguous behaviors, cognitive capabilities and } \\
\text { diversified reactions to external stimuli. } \\
\text { 4.3. Admit, in advance and in an inclusive way, } \\
\text { ethic- anthropometric capabilities, before (the wish } \\
\text { of), during, and after the use (the evaluation of). } \\
\text { 4.4. Admit in advance and in an inclusive way } \\
\text { handicaps and disabilities (even temporary ones). }\end{array}$ \\
\hline $\begin{array}{l}\text { 5. Make aesthetically beauty } \\
\text { products, environments, systems } \\
\text { and/or processes. }\end{array}$ & $\begin{array}{l}\text { 5.1 Make aesthetically harmonious the different } \\
\text { elements in order to make synesthetically pleasant } \\
\text { conceptual and operative schemes. }\end{array}$ \\
\hline
\end{tabular}




\begin{tabular}{|c|c|}
\hline & $\begin{array}{l}\text { 5.2. Show equilibrate and perceptually congruous } \\
\text { details for allowing the end-users' autonomous } \\
\text { fruition. } \\
\text { 5.3. Make the aesthetic of the solution adaptable to } \\
\text { end-users' aspirations, needs and market evolution. } \\
\text { 5.4. Make the aesthetic of the solution so as not to be } \\
\text { perceived as "designed only for a specific end-users } \\
\text { group". }\end{array}$ \\
\hline $\begin{array}{l}\text { 6. Make socially, } \\
\text { environmentally and } \\
\text { economically sustainable, } \\
\text { products, environments, systems } \\
\text { and/or processes. }\end{array}$ & $\begin{array}{l}\text { 6.2. Make the intervention socially suitable, valid } \\
\text { and justified compared to generable social impacts. } \\
\text { 6.2. Show the intervention as a fundamental part of a } \\
\text { socially aware, inclusive and respectful of } \\
\text { stakeholders' needs. } \\
\text { 6.3. Make the intervention environmentally suitable, } \\
\text { valid and justified compared to the conservation of } \\
\text { involved ecosystem's equilibrium. } \\
\text { 6.4. Make the intervention economically suitable, } \\
\text { valid and justified compared to the expected } \\
\text { economic efforts. }\end{array}$ \\
\hline $\begin{array}{l}\text { 7. Improve the end-users' } \\
\text { quality of life. }\end{array}$ & $\begin{array}{l}\text { 7.1. Enhance end-users' ethnic-anthropometric } \\
\text { capabilities. } \\
\text { 7.2. Enhance end-users' psycho-cognitive and } \\
\text { interpretative-cultural capabilities. } \\
\text { 7.3. Enable end-users' disadvantageous physical } \\
\text { conditions, such as: impairments, handicaps and }\end{array}$ \\
\hline
\end{tabular}




\begin{tabular}{|c|c|}
\hline & $\begin{array}{l}\text { disabilities (even temporary ones). } \\
\text { 7.4. Empower end-users' diversified capabilities and } \\
\text { reaction times to external stimuli. }\end{array}$ \\
\hline $\begin{array}{l}\text { 8. Include all potential end-users } \\
\text { in the design process. }\end{array}$ & $\begin{array}{l}\text { 8.1. Promote, through collective and aware decision- } \\
\text { making processes, the access and the use of services } \\
\text { and essential solutions in an aware and responsible } \\
\text { way. } \\
\text { 8.2. Support in a synergic way - and promote the } \\
\text { collective effort and engagement of all potential } \\
\text { stakeholders - the interaction and the intervention of } \\
\text { stakeholders at their most appropriate level. } \\
\text { 8.3. Promote the collective cooperation of all } \\
\text { potential stakeholders and decision makers, the } \\
\text { socialization and the establishment of shared } \\
\text { networks, in order to optimize the access to } \\
\text { meaning of weakness), the equity during the } \\
\text { resources. } \\
\text { interventions. }\end{array}$ \\
\hline
\end{tabular}


Table 2. HSDT in Interaction Design domain for the topic 'allow the continuous gestures' self-learning'.

\begin{tabular}{|l|l|}
\hline Original Definition (before HSDT) & $\begin{array}{l}\text { Inclusive-oriented Definition (after HSDT) } \\
\text { (improvements are shown in 'bold') }\end{array}$ \\
\hline $\begin{array}{l}\text { Allow the continuous gestures' self- } \\
\text { learning. }\end{array}$ & Allow the continuous, aware and \\
gratifying gestures' self-learning.
\end{tabular}


Table 3. HSDT in Knowledge Management domain for the topic 'represent and detail existing tacit knowledge, including its themes and aims'.

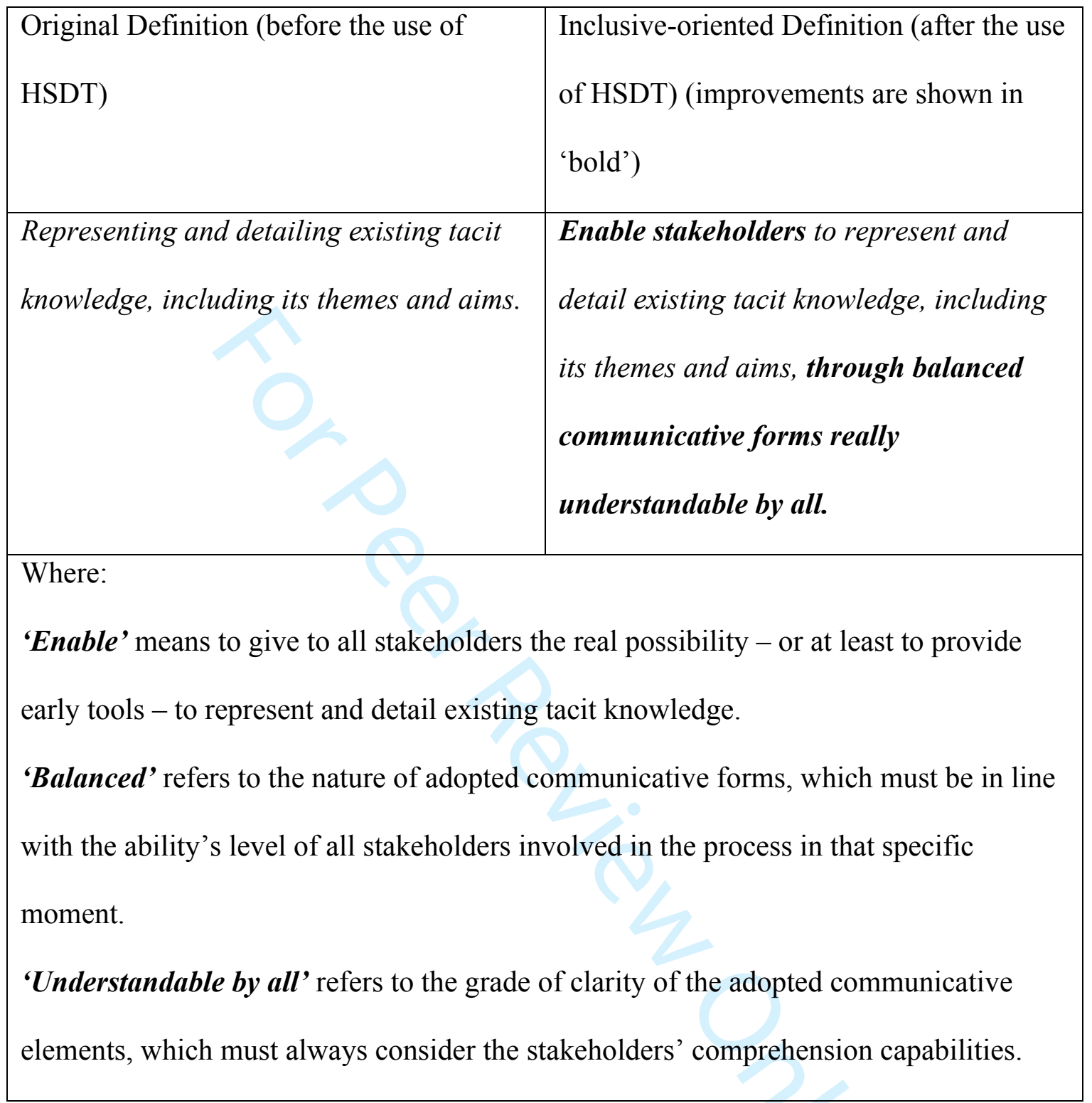

